\title{
Genetics analysis and management of mosquito control
}

\author{
Habeeb M. Al-Solami \\ Department of Biological Sciences, Faculty of Science, P.O. Box 80203, King Abdulaziz University, Jeddah, 21589, Saudi Arabia
}

Correspondence Author: Habeeb M. Al-Solami, Department of Biological Sciences, Faculty of Science, P.0. Box 80203, King Abdulaziz University, Jeddah, 21589, Saudi Arabia

Email: hmalsolami@gmail.com

Received date: 20 June 2019, Accepted date: 2 August 2019, Online date: 25 August 2019

Copyright: (c) 2019 Habeeb M. Al-Solami, This is an open-access article distributed under the terms of the Creative Commons Attribution License, which permits unrestricted use, distribution, and reproduction in any medium, provided the original author and source are credited.

\begin{abstract}
The modern and associated multiplication of mosquitoes around the world, based on ecological and anthropological characteristics and fed by diseases derived from mosquitoes, is costly for applicability to a public space. It becomes a proposition. The debilitating diseases of man and, worse still, the victims and death, make it an urgent priority in this complex trial. WHO four astronomical malaria-infected by many mosquitoes, dengue fever and attention to yellow fever drew from all over the world, the association of public participation and its ambitious efforts are the main factors in reducing mosquito problems, all voters in the community and all citizens should participate in the fight program to strengthen public education by simulating the leverage needed to achieve positive results. In terms of water management programs, Saudi Arabia is not the place to fight mosquitoes because of its geographical location, weather conditions and the amount of water exposed in the center. commercial. Due to the increase in the mosquito population. The purpose of this review is to provide an overview of the amount of genetic diversity that exists among them for use in the management of mosquito lineage and mosquito control.
\end{abstract}

Keywords: Genetics analysis, management, mosquito, control

\section{INTRODUCTION}

Clearly say and exclusively: "Recognize your enemies!" However, in the case of insects, and deeply rooted or built in the field of ecology, there is no "sadness" or "sadness" for any ecological problem whatsoever. Absolute and balanced against insects in complex aspects of the environment. Environment and nature in general. The argument in addition to that, it's always easier to say what to do, what can be called anecdotes. Sound logistic approaches to mosquito control reduce, prevent or minimize the destructive or destructive effects of these mosquitoes. It is called the reasonable use of different methods compatible with the objective. The intrusion of insects invading the human neighborhood the epics will continue forever because these mighty creatures are endowed with powerful functions that provide the benefits of the resurrection, the flame of luxury with repetition and that of the creator. It is natural for people to be able to use all their repertoire and innovative weapons to prevent and resist acute attacks on heavy health products. These innate abilities and properties give them the security of these insects [1]. Life and they tend to give rise to different goals, with sophisticated and resilient genetic constructions that are manipulated to win a violent war with peoples based on their own purposes.

Current and significant management of mosquitoes relies on Integrated Management (IC), Integrated Mosquito Management (IMM) or Integrated Mosquito Management (IMA) programs. And all of these include secret words for the management and tactics of Integrated Pest Management (IPM) strategies. The rational management of water is a unique solution to reduce the sources of mosquitoes. Today, mosquito-borne diseases are one of the leading causes of death among the most feared populations in the world. WHO, clinical case of over 300 million each year is estimated to be due to dengue by 5,000 million cases of the disease and mosquito, in a sense, mosquito control activities are directly related to public health, and there is a growing interest in ecological and environmental impacts that aggravate the problems of pest resistance. Emphasize the need for integrated pest management. Reputation Group Environmental Protection Agency (EPA) and CDC (Disease Management Center) claim to adhere to Integrated Pest Management (IPM) most as an ecological strategy based on the use of natural death factors to study tactics [2]. The control is compatible or modified with these factors. As small as possible IPM uses chemical pesticides, but systematic monitoring and recognition of problematic mosquito populations indicate that there is a need for an IPM that considers 
all available control actions, including behavior. Therefore, it's more important. Evaluate the interaction between different control applications. It is used in combination with robust resource management techniques presented as a decision to monitor the population of fragile ecosystems: Cultural Climate and Habitat Structure Integrated system [3].

The rational management of mosquitoes, two sustainable management plans, because it also contains the managed epithelium called Eden mosquito, integrated management is integrated ecologically in management strategies interdisciplinary methodologies economic and based on social norms. Pest Public Health, Protect the Environment, Quality Life Improve for Convenient and Effective. All approaches are used with pesticides causing mosquito shedding, including active and practical physical control [2].

Besides, family and community education is an integral part of the main benefits of the protected area. These people, as an essential part of public education, which is organized as follows, you must understand the mosquito control strategy. support. Residents must understand mosquitoes and their life cycle. Residents need to know that the real benefit is the future of mosquito control. The human is rolled in the prevention of mosquito-borne diseases. All these points must be carefully considered in view of the time elapsed since the insecticides can be used. Public education can be achieved using social media that requires educated professionals to educate through public school campaigns, awareness campaigns, and design awareness programs. Local citizens' groups, community leaders, public health agencies and news kiosks should play a larger role and benefit from festivals and conferences. Recommendations for mosquito prevention should be published in media such as newspapers, the internet, radio, and television. As part of the public education program, homeowners should receive updates on hangars and information materials. Finally have knowledge in biology, mosquito control method play report copy and maybe have shelter in housing as mosquitoes, most breeding areas are removed from their territory, neighbors can do the same [3]. The aim of this review focus on genetics analysis and management of mosquito control.

\section{The nature of Saudi dengue}

Given the climatic conditions and the ecological orientation of western Arabia, the problem of mosquitoes is not severe in everyday life compared to Florida, Equatorial Africa or the rich. It is teeming with savannahs in the tropics, subtropical regions of the world, fresh surface waters of rivers, lakes, ponds, abundant vegetation, and heavy rainfall. In an extremely enthusiastic ecosystem, intensive spills create a utopia that leads to the astronomical level of accumulation of mosquito populations.

So, Western Saudi Arabia has a hot, dry climate for most of the year, with low rainfall and low vegetation covering most areas, including valleys and inhabited areas. Therefore, as an unstable and sensitive ecosystem can define. Relates to dengue and vector, Red sea bream, Egypt, in addition to the preventive and preventive measures taken by the government and the citizens, updated data have been published to show or show the full range of intrusions.

Mosquitoes are of great concern because of mosquito-borne diseases. So usually it's the type of mosquito. To do less than between the highest level of discomfort with a bite infection between human disease is often sporadic for this purpose. In most cases, depending on climate and environmental conditions. Even though the government conducted thorough maintenance. Between caring ton take this sporadic aggression between Attainders Epidemiology Level. Dengue outbreaks are not a daily problem caused by unknown tears due to unconfirmed symptoms that the unsuspecting owner or technical surveillance team may ignore for the following reasons: These incidents will be clear. Traditional surveillance is based on cases and deaths recorded by health agencies, but unfortunately, estimates from surveillance data are systematically inferior to samples due to lack of reporting and miscalculation death [4-5].

Population sampling and distribution measurement dorado red netted Simona for the immature population (larva and fairy), index of houses (percentage of houses invaded), container index (proportion of flooded water containers), Bertheau directory (Plus less containers/ 100 units) directory (number Ovi- Positive (placement trap arrangement/ 100 units) However, adult surveillance, feather (drop rate per index drop per hour (one person) and rest intensity ( adult mosquito/time or number of adults collected / unit time, Lloyd, 2003)). Red sea bream Nettai Simona in the absence of vaccines and treatments, dengue and chikungunya are very important mosquitoes criticized for their transmission of yellow fever. Summarize These Modern Efforts Included for Mosquito management: a, 2 touch control chemical vector, the first way for mosquitoes A caterpillar A killer larvae method for use with low toxicity insecticides. The second method involves the use of chemicals to kill adult mosquitoes' adult killers). Success B. Environmental Management, Environmental Change, Operations, and Emergency priorities include modifying or modifying the environment to reduce or reduce mosquito growth. The habits and human behavior, this may take the form of an environmental management project government offspring public projects in which community participation has recently gained popularity, as they are thought to play an essential role in public participation in current programs, rational logistic management. British Oxitec Ltd and California scientists working at universities in Irvine use a powerful genetic approach to develop mosquitoes that safely reduce or eliminate the spread of diseases transmitted by humans.

\section{Mosquitoes:}

In women, mosquitoes cannot fly in a mosquito-controlled approach and help to create new breeds. Enthusiastic female mosquitoes are expected to die soon in the wild, reducing the number of mosquitoes reducing or eliminating transmission groups. Men of this breed can fly but do not bite and do not transmit disease. Reported by up talk other. As of 2013, Ensemble of Physical, Chemical, Biological, and Hybrid Methods allow the synthesis of various types of silver, gold, zinc and platinum nanoparticles. Physical and chemical methods are ubiquitous and widely used in nanoparticle synthesis, but the associated ecotoxicity and non-biodegradable nature of the products limit its use. Thus, the "green" synthesis of plant-based nanoparticles is of great interest because of its ecological consequences, its economic prospects, its applicability and its full wide application [6]. Nanotechnology has been widely used in vector control. Nanocapsule when Nanosensor for detection of parasites [7]. The synthesized silver or gold nanoparticles are also useful to produce new insecticides and insect repellents. Nanotechnology applications are environmentally acceptable Plant Extract Of silver and gold nanoparticles from water and mosquitoes that deplete 
ecosystems. The control of mosquitoes has spread, presents a unique view of the molecular mechanisms that control the reproductive behavior of mosquito species. They reported that reproductive inefficiency controlling the seminal fluid protein gene produced in the male accessory gland (MAG) significantly affects reproduction and reproductive survival. The focus is on the molecular mechanisms that regulate the reproductive biology of puppies and mosquitoes. Demonstrate opportunities and new advice to develop genetic and chemical the vector control of measures innovator solution, an ethicist to control and eliminate infections, particularly in the poorest regions of the world.

Many scientists in the field of mosquito research have included advanced tools for procedures such as molecular entomology and cell biology and the genetic and physical mapping of germline transmission processes, such as the defence of insects. Against pathogens [8]. May contain non-vector species Complex Species or species of different species with distinct heterogeneity of endemic species Other studies have been made to be deciphered. This phenotypic and genotypic plasticity may exacerbate the identification difficulties that affect surveillance and control strategies. Protein chromosome studies are one of the first countries to provide specific genetic markers to distinguish recognized species from other chromosomal forms of mosquitoes, [9].

\section{Genetically modified mosquitoes:}

Genetically modified mosquitoes (GM mosquitoes) are species-friendly and can use sterile insect technology (ASSEOIR), a specific method of insect control. It is defined as "contraception" for insects successfully used in agriculture. More than 50 years old Genetic material is a genetically modified organism (GM organism) that is often altered using genetic techniques known as "recombinant DNA technology." No genetic modification allows scientists to calculate genes and DNA segments accurately and accurately to achieve the desired result. It is a safe and well-understood technology that does not pose a natural hazard to the process. Recombination of this DNA segment requires another name for the same technology, namely recombinant DNA technology. Therefore, all GMOs must consider that they must go through comprehensive scientific testing and a complete and appropriate regulatory process before their use is permitted. Merit use between Logitech mosquito by relevance the other method of control is as follows. POPE potential for the decline of the population Nettie Simona at a low level itself Infected Patient does not. It is a less expensive and more effective biological control method than killing women using chemical vaporizers or missing equipment. At the same time, it is an environmentally friendly approach with less impact on the environment. There is no permanent change in the wild mosquito population, compared to currently used alternatives; it is less likely to affect the environment. Killing mosquito larvae accurately is a gene that crosses the mosquito and prevents cells from functioning correctly.

Arrangements for the public release of genetically modified organisms are governed by national laws and regulations (biosecurity). The Cartagena Biosafety Protocol is an international treaty governing the movement of GMOs between countries. Me Addition, UN Uni National Insect Development Program Genetic Recombination It Offers More Education and Training [10].

\section{Biological control:}

Biological control methods include the use of mosquito control organisms to reduce the size of the vector population. Many examples are being tested, including invertebrate copepods (small crustaceans) that can be added to tanks and larvae. Gambusia affined BTI Biocides are unusual bio-expanded pesticides that are widely used around the world. The main advantage of biological control methods is that sometimes certain types do not cause chemical contamination of the environment. They do not affect other ecosystems. Also, the cost of breeding organisms may be high, but their use is usually limited to a limited number of cases.

It has already been shown that drug development and drug resistance are a significant challenge, threatening the success and sustainability of pesticides between Innovative Management Measures. I read et al. 2010 has developed a combination of synthetic chemical attractors that can attract more Andalucía by creating an extensive capture system that attracts mosquitoes large enough to contain the size of the population, it is a revolutionary human that reduces the strength of promising roads. led to a significant increase in control by collectively collecting mosquito vectors. The smell of these foods mimics the human smell $[11,12]$.

Chavarria [13] Announces Next Generation Nano Layer Development Explicitly designed as an insect repellent paint to repel insects and other arthropods, it reduces its presence and proliferation and prevents its growth and reproduction. At the community level, tactics and strategies need to be implemented by involving citizens in educational programs using old media and telecommunications. Electronic alarm, electronic information about the mosquito problem.

\section{Disease Vector}

While most Swedish mosquitoes are vectors of possible diseases, Sweden has survived the major mosquito-borne conditions. Exceptions include malaria caused by malaria. Parasite of malaria SP. It was popular until the 19th century, and present why Sindbad Virus This affects a few people each year. The main vector is a genre when to Closet [14], but recent studies show that it is probably just as important that the virus resolves [15-18]. While the weather in northern Europe becomes more rainy and warmer, Andalucía may again bring type malaria parasite [19]. In Sweden, the risk of new arboviruses increases.WMF is a zoonosis caused by VNO, a single-stranded RNA virus of this genus. Flavivirus. When the main host moves infected birds and birds, the infection can spread to new areas. A female mosquito caught the virus and infected other birds, reptiles and mammals, including humans. Although VNO- infected individuals are generally asymptomatic, on $20 \%$ of WMF patients are infected with WNF and 1\% Nerve - west Nile Invasion with Encephalitis [20]. There is currently no human vaccine available. This virus is common and has been established in Africa, Oceania, North America, South, and Central Asia and Southern Europe [21] and occur annually.

Mosquito species of the genus. Jeda When to Cueillette Richard (CQ Richard) They are accepted the main vectors of VNO [22] CQ. Richard and vector complex numbers Jeda Patience (CX Patience) They are estimated WNV carriers in Sweden Wild 
gonorrhea is derived from bacteria. In Sweden, it causes an epidemic each year the mechanism of bacterial spread is currently unknown, they are exposed to bacteria through protozoa [23]. Warm weather can also cause mosquito species to enter new areas. "Tiger Mosquito", Aedes albopictus. Seed with the subtropical tropics in southern Germany, WMF is a vector of scores for various arboviruses that can cause diseases such as rift valley fever and dengue fever.

\section{Conclusions}

The need for new innovations to combat emerging diseases and pests has never been higher, and this is an exciting time for science and research in the field of insect genetic control. Some of the GM technologies described in this review were tested in the field. The next wave of molecular methods concerns disease-carrying mosquitoes, and this is beginning to strike important species for agriculture. Particular attention is paid to regulatory issues to ensure the safe and proper implementation of these genetically engineered genetic strategies. Taken together, these developments create new hopes for greater agricultural and socio-economic benefits. The expectation of genetic control methods against mosquito vectors Human diseases is fast approaching. With potential. Another promising method against dengue and/or malaria There must be many national, regional and international decisions regarding biosafety as well as social, cultural and ethical aspects of the use and dissemination of these vector control methods.

\section{CONFLICT OF INTEREST}

The authors declare no conflicts of interest.

\section{ACKNOWLEDGMENT}

The authors support from the Dept. of Biological Sciences, Faculty of Science, King Abdulaziz University (KAU), Jeddah, KSA.

\section{REFERENCES}

1. Erik Helmersson 2013. Molecular identification of mosquito species Evaluation of a rapid DNA extraction method together with DNA barcoding as a tool for identification of species, Degree project in biology, Bachelor of science

2. El-Badry, Ayman A. \& Hesham A. El-Beshbishy \& Khalil H. Al-Ali \& Ahmed M. Al-Hejin \& Wael S. M. El-Sayed 2014. Molecular and seroprevalence of imported dengue virus infection in Al-Madinah, Saudi Arabia, Comp Clin Pathol (2014) 23:861-868.

3. Jana Batovska, Mark J. Blacket, Karen Brown \& Stacey E. Lynch, Molecular identification of mosquitoes (Diptera: Culicidae) in southeastern Australia. Ecology and Evolution 2016; 6(9): 3001-311.

4. Gubler, D. 1998. 'Dengue and Dengue Haemorrhagic Fever' Clinical Microbiology Reviews. Page 480 - 496.

5. Guha-Sapir, D. and Schimmer, B. 2005. 'Dengue Fever: New Paradigms for a Changing Epidemiology' BioMed Central.

6. Salam, H.A., Kamaraj, R.P.M., Jagadeeswaran, P., Guanalan, S., Sivaraj, R. Plants: green route for nanoparticles synthesis. Int Res J Biol Scie 2012; 1(5); 85-90.

7. Scrinic, G., Lyons, K. 2007. The emerging nano-corporate paradigm: Nanotechnology and the transformation of nature, food and agri-food systems. Int J Sociol. Food Agric. 15(2); 22-44.

8. Collins, F.H., Kamau, L., Ranson, H.A., and Vulule, J.M. 2000. Bull. World Health Organ. 2000; 789120:1412-23.

9. Norris, D.E. 2012. Genetic markers for study of anopheline vectors of human malaria. Int. J. Parasitol. Dec 4;32(13):1607-15

10. Harris, F. III, \& Wood, J. L. (2013). Student success for men of color in community colleges: A review of published literature and research, 1998-2012. Journal of Diversity in Higher Education, 6(3), 174-185.

11. Jawara, M., Smallegange, R.C., Jeffries, D., Nwakanma, D.C., Awolola, T.S., Knols, B.G., Takken, W., and Conway, D.J. 2009. Optimizing ordor-baited trap methods for collecting mosquitoes during the malaria season in The Gambia. PLoS ONE 2009., 4 PubMed Abstract.

12. Mukabana, W.R., Mweresa, C.K., Otieno, B., Omusula, O., Smallegange, R.C., Loon, JJAv., Takken, W. 2012. A novel synthetic odorant blend for trapping of malaria and other African mosquito species. J Chem Ecol 38:235-244.

13. Chavarrja, B.C. 2013. NanoLabs Unveils Natural Insect Control in Innovative Paint Coating. Nano Labs Corp.

14. Lundstrom, J.O., Niklasson, B.O., Francy, D.B., 1990, Swedish Culex torrentium and Culex pipiens (Dipitera: Culicidae) as experimental vectors of Ockelbo virus. J. Med. Entomol. 27, 561-563.

15. Lundstrom, J.O., Pfeffer, M., M., S., Persson Vinnersten, T.Z., Forsberg, B. 2007. Sindbisvirus förekommer hos stickmyggor i Avestaområdet, vid Färnebofjärden, vid Hedesundafjärden och vid Storfjärden. (Uppsala, Uppsala University).

16. Lundstrom, J.O. 2006. Ekologiska risker vid bekämpning av stickmygglarver med BTI iöversvämningsområden (Uppsala, Uppsala University).

17. Lundstrom, J.O., Andersson, A.C., Backman, S., Schafer, M.L., Forsman, M., Thelaus, J., 2011, Transstadial Transmission of Francisella tularensis holarctica in Mosquitoes, Sweden. Emerging Infect. Dis. 17, 794-799.

18. Turelli, J.J. 2013. Wolbacchia versus dengue evolutionary forecasts. Evolution, medicine and public health. Emph.oxfordjournals.org

19. Jaenson, T.G.T., Lokki, J., Saura, A., 1986, Anopheles (Diptera, Culicidae) and Malaria in Northern Europe, with Special Reference to Sweden. J. Med. Entomol. 23, 68-75. 
20. Davis, L.E., DeBiasi, R., Goade, D.E., Haaland, K.Y., Harrington, J.A., Harnar, J.B., Pergam, S.A., King, M.K., DeMasters, B.K., Tyler, K.L., 2006, West Nile virus neuroinvasive disease. Ann. Neurol. 60, 286-300.

21. Dauphin, G., Zientara, S., Zeller, H., Murgue, B., 2004, West Nile: worldwide current situation inanimals and humans. Comp. Immunol., Microbiol. Infect. Dis. 27, 343-355.

22. Hayes, E.B., Komar, N., Nasci, R.S., Montgomery, S.P., O'Leary, D.R., Campbell, G.L., 2005, Epidemiology and transmission dynamics of West Nile virus disease. Emerging Infect. Dis. 11, 1167-1173.

23. Lundstrom, J.O., Andersson, A.C., Backman, S., Schafer, M.L., Forsman, M., Thelaus, J., 2011, Transstadial Transmission of Francisella tularensis holarctica in Mosquitoes, Sweden. Emerging Infect. Dis. 17, 794-799.5 